\title{
A NEW GENUS OF SUCKING LICE,
}

By Eric MJöberg

\section{Hamophthirius n. g.}

Antennæ three-jointed, first joint very strongly developed, with a large chitinous hook; head anteriorly very strongly constricted, with a strong and sharp chitinous hook on each side, posterior half transverse, nearly twice as broad, posterior angles protruding, forming two processes, posterior margin strongly emarginate on each side of the middle; thoracic segments coalescent, parallel-sided, all pairs of legs fairly equally developed; abdomen of normal type, with pleural scelerites developed on segments two to six. Integument scaly.

Type, the following species:

Hamophthirius galeopitheci n. sp. (Fig. 1.)

Yellowish, depressed; head in front strongly chitinized; lateral hooks parallel, very sharp; antennæ with the first joint enormously developed, with a very large hook and ventrall yon the posterior margin with a smaller one; second joint shorter than the third, both nearly parallel-sided; third joint with two lateral sensitive fossæ, its terminal field with eight to ten sensitive seta-like organs. On the ventral side of the head posteriorly there is a dagger-like spine at each side; posterior lower angles obtuse, the upper angles distinctly produced, rounded at the tips, and provided with three long setæ. Thoracic segments coalescent, anterior angles of prothorax rounded; at the middle of the anterior margin deeply excised to receive the corresponding protruding part of the occipital region of the head; legs moderate in size, fairly equally strongly developed; tibiæ with four small terminal chitinous spines opposite to the claw; claws large, distinctly striated (fig. 1, b). Abdomen in both sexes of normal development; pleural scelerites small, posteriorly emarginate (fig. 1, c and d); tergites and sternites with two more or less regular rows of fine depressed setæ. Chitinous parts of genitalia in $\sigma^{7}$ (fig. 1, e) forming two parallel jointed rods, simple gonapods 
of normal type, forming two flat lobes of more or less triangular shape and provided with numerous chitinous setæ; last segment produced into two small, unjointed processes.

Length of body: $0^{7} 1.7 \mathrm{~mm}$; $\% 2.5 \mathrm{~mm}$. (Fig. 1, f).

Eggs: Oval, whitish, with a series of faint transverse ridges on the upper half, the top set off as a distinct micropyle field with numerous small protruding tubercules in a row.

This remarkable form of louse which offers in its external general appearance a striking resemblance to the mallophagan

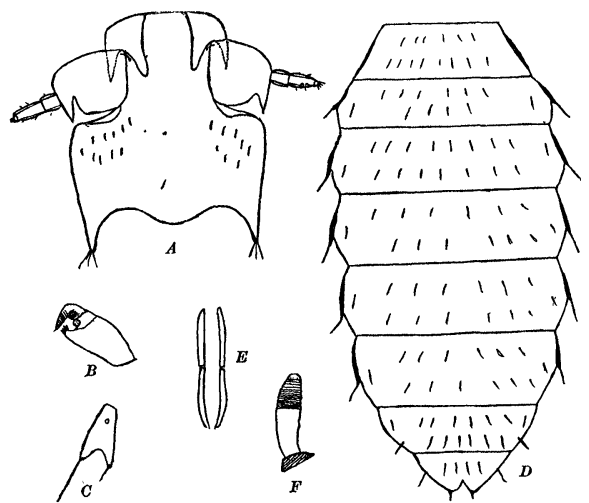

Fig. 1. Hamophthirius galeopitheci n. sp. A, head; B, tarsal claw; C, pleural sclerite; D, abdomen; E, genital rods of male; F, egg.

genus Trichophilopterus Stobbe in possessing strong chitinous hooks on the head and antennæ, was taken by me near Fesseltan in British North Borneo on a freshly shot Galeopithecus sp. Like its host it occupies a very isolated position and it is difficult to place it even in one of the known families. The mouthparts are very delicate but mainly of the same type as in other Anoplura. The three-jointed antennæ and the strongly developed chitinous hooks as well as the general shape of the head point to a high degree of specialization. 

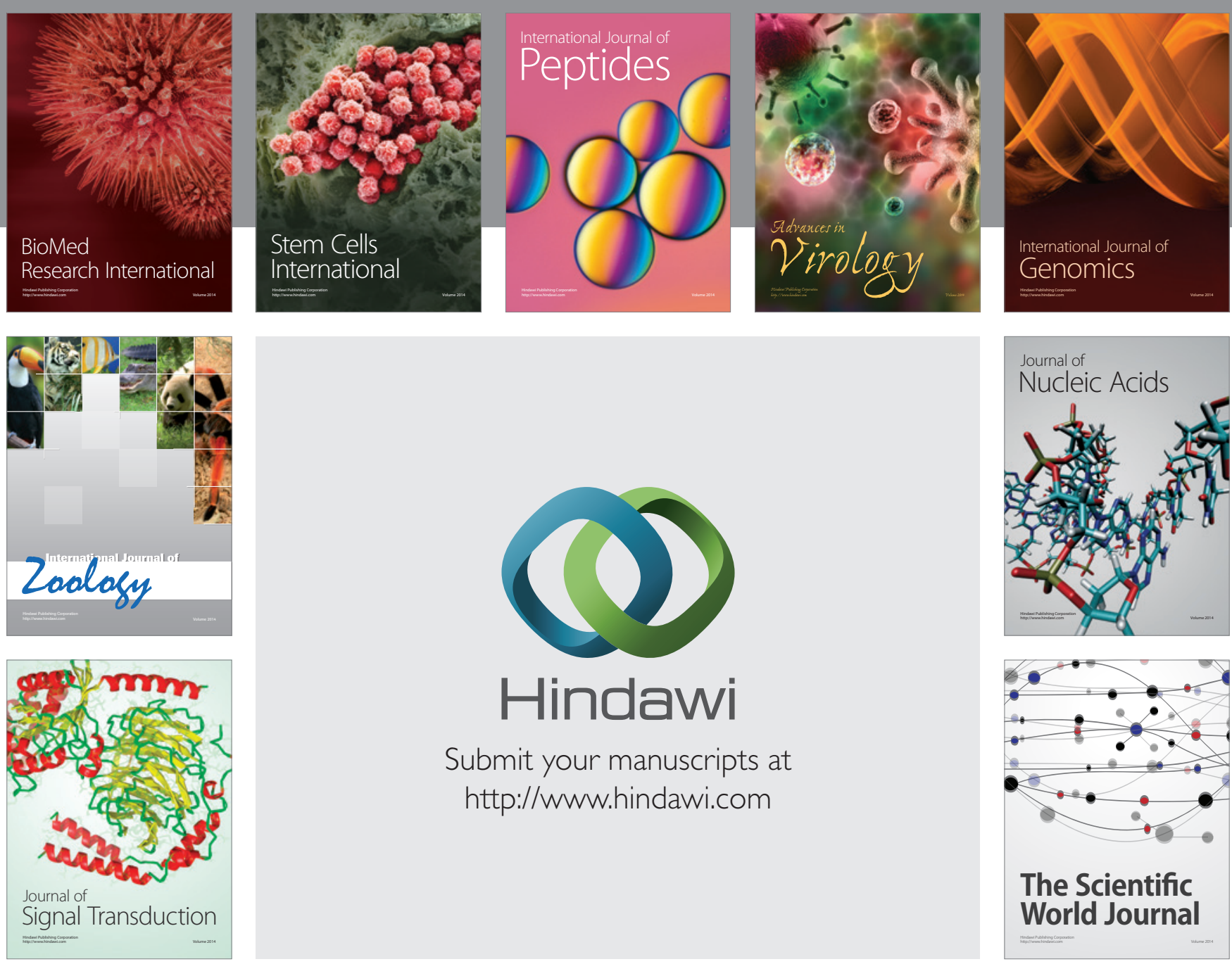

Submit your manuscripts at

http://www.hindawi.com
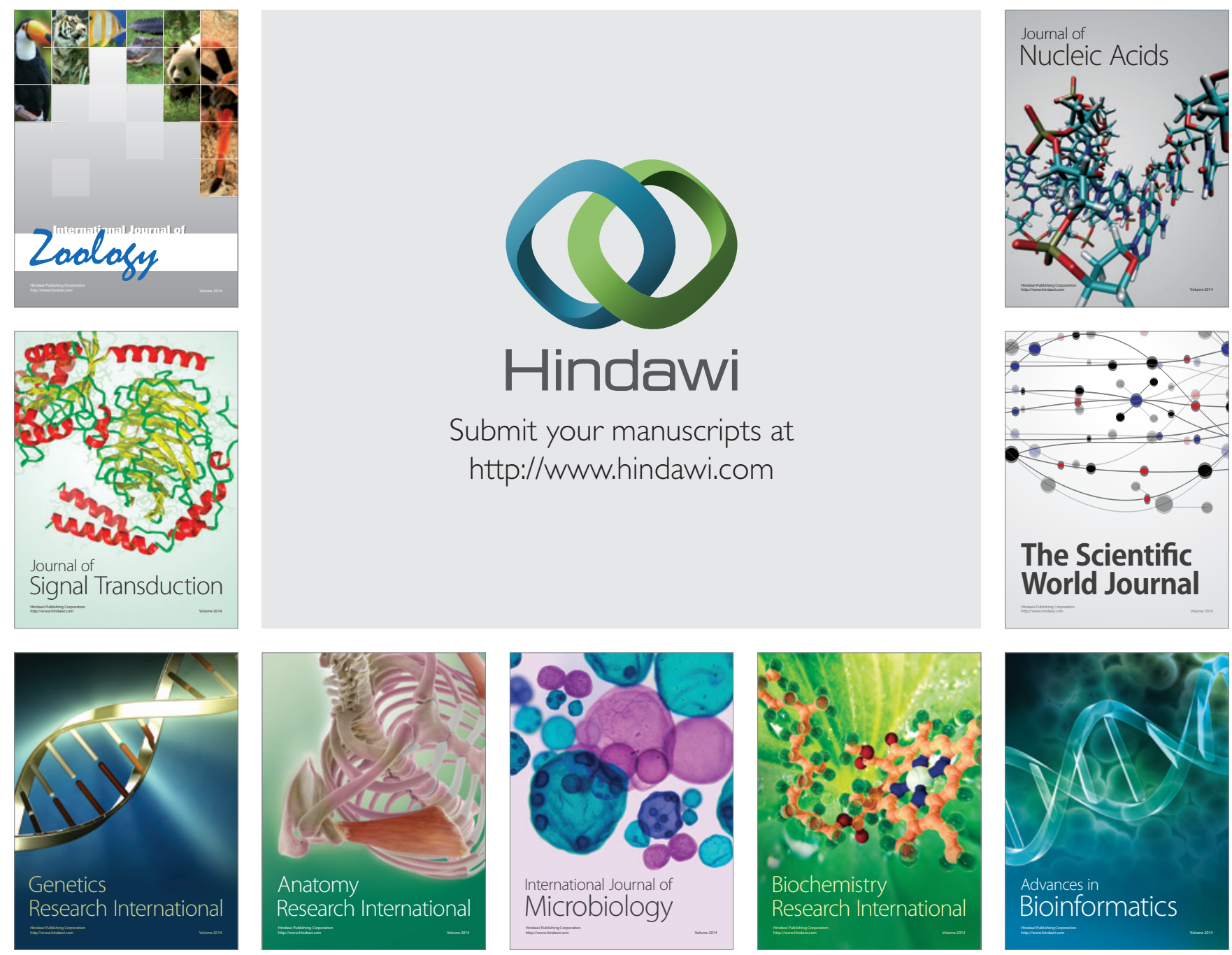

The Scientific World Journal
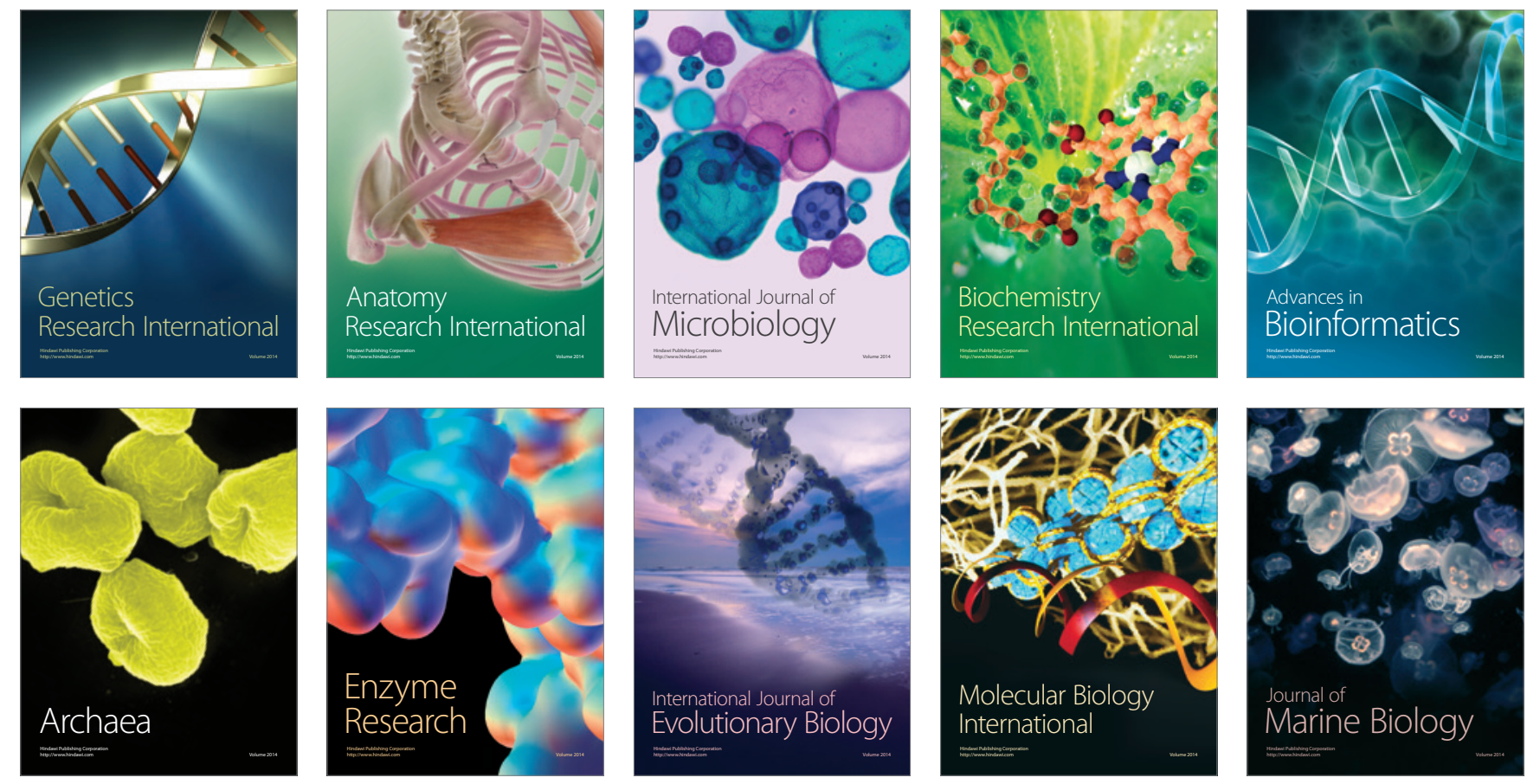